\title{
LA PEDAGOGÍA DE LA IMAGEN: LAS LÁMINAS ESCOLARES COMO RECURSO HISTÓRICO Y MUSEOGRÁFICO EN LA HISTORIA DE LA EDUCACIÓN
}

\author{
María Cristina Linares \\ Universidad Nacional de Luján/Argentina \\ mariacristinalinares@yahoo.com.ar
}

\begin{abstract}
RESUMEN
Las transformaciones en el campo de la técnica permitieron que el recurso de las imágenes impresas fuese masivo a partir del siglo XIX. La invención de la litografía en 1798, permitió ampliar el número de las reproducciones bajando costos y, en el marco de la revolución industrial, la creación de empresas que se dedicarían a producirlas. Por otro lado, la creación de los sistemas nacionales de educación y la homogenización de contenidos promovieron la expansión de la producción de láminas escolares en el último cuarto del siglo XIX. Desde el punto de vista de la pedagogía, el uso masivo de las imágenes como medio didáctico tiene apenas un poco más de un siglo, aunque podemos rastrear sus orígenes en el siglo XVII. Las láminas escolares tuvieron protagonismo hasta las décadas de 1970/1980 cuando por razones epistemológicas y didácticas muchas de ellas pasaron a formar parte de museos y archivos. La escuela utilizó láminas- en algunos casos las sigue usando - como medios didácticos para la enseñanza, llevando el mundo exterior, muchas veces inalcanzable, a los muros del aula. Nuestra intención es contribuir al recorrido histórico de este auxiliar escolar, y reflexionar sobre las posibilidades de guarda y expositivas en los museos.
\end{abstract}

Palabras-clave: Láminas escolares. Historia. Exhibición. Museos.

\section{VISUAL EDUCATION: WALL CHARTS AS HISTORIC AND MUSEOGRAPHIC RESOURCE IN THE HISTORY OF EDUCATION}

\begin{abstract}
The changes in the technical field allowed the appeal of the printed images would be massive at the beginning of XIX century. The invention of lithography in 1798, made it possible to expand the number of reproductions by lowering costs and, in the framework of the industrial revolution, the creation of companies that would be devoted to produce them. On the other hand, the creation of national systems of education and the homogenization of content promoted the expansion of the production of wall charts in the last quarter of the nineteenth century. From the point of view of pedagogy, the massive use of the images as a teaching tool has only a little more than a century, although we can trace their origins in the seventeenth century. Wall charts had prominence until the decades of 1970/1980 when by epistemological and didactic reasons many of them became part of museums and archives. The school used wall charts - in some cases still used - as teaching aids for teaching, bringing the outside world, often unattainable, in the walls of the classroom. Our intention is to contribute to the historical route of this school assistant, and reflect on the possibilities of saves and exhibition in museums.
\end{abstract}

Keywords: Wall charts. History. Exhibition. Museums. 


\section{DE LA PEDAGOGÍA}

Las escuelas enseñan las palabras antes que las cosas [...], siendo así que las cosas son substancia y las palabras el accidente; las cosas el cuerpo, las palabras el vestido, las cosas la médula y las palabras la corteza y la cáscara. Deben presentarse juntamente unas y otras al entendimiento humano; pero en primer lugar las cosas, puesto que son el objeto, tanto del entendimiento como de la palabra. (COMENIO, siglo XVII, 1986, p 125).

A partir del siglo XIX las transformaciones en el campo de la técnica permitieron que el recurso de las imágenes impresas fuese masivo. La invención de la litografía en 1798 permitió ampliar el número de las reproducciones bajando costos y, en el marco de la revolución industrial, la creación de empresas que se dedicarían a producirlas. Por otro lado, la creación de los sistemas nacionales de educación y la homogenización de contenidos promovieron la expansión de la producción de láminas escolares en el último cuarto del siglo XIX.

Desde el punto de vista de la pedagogía, el uso masivo de las imágenes como medio didáctico tiene apenas un poco más de un siglo, aunque podemos rastrear sus orígenes en el siglo XVII con la obra de Juan Amós Comenio (1592-1670).

Comenio formaba parte de la reforma religiosa protestante que se propuso crear una tradición pedagógica para hacer frente a la educación católica y jesuítica. Afirmaba que no existía una metodología que tuviera en cuenta el desarrollo de la ciencia, particularmente del empirismo de Bacon que proponía una nueva lógica para conocer utilizando la percepción y la experimentación, aplicando el método inductivo, es decir, llegar a conclusiones generales a partir de enunciados particulares. En este marco empirista Comenio desarrolló la idea de que las palabras mismas deben derivarse de los objetos de la experiencia personal.

Una vez establecido su método, Comenio buscó las herramientas para llevarlo a cabo. Establecía que era necesario presentar o representar todo por medios sensibles: “[...] el que presenció con atención una sola vez la anatomía del cuerpo humano, comprenderá y recordará todas las cosas con mayor evidencia que el que hubiera leído muchos y más extensos comentarios sin la inspección ocular" (COMENIO, 1986, p. 200). 
En caso de no disponer del objeto natural, aconsejaba la utilización de cuadros, pinturas, modelos y reproducciones a escala.

Es dentro de esta concepción que Comenio publica el Orbis sensualium pictus (El mundo sensible en imágenes), "nuestra pequeña enciclopedia de las cosas sensibles" según Comenio. Convencido de que nada entra en el intelecto si no es por medio de los sentidos, pensó en producir una nueva ayuda para las escuelas. Un libro pequeño, enciclopédico, que podía utilizarse para enseñar todo a todos, y con su contenido organizado en torno a las imágenes de los objetos, sus nombres y sus descripciones. Un libro con el texto dispuesto en dos columnas, una en latín y la otra en alemán. Al año siguiente, la obra se publicaría en Inglaterra en versión latina e inglesa. Este libro es considerado el primer texto escolar con imágenes

Las ideas de Comenio recién serán tomadas en cuenta a fines del siglo XVIII y principios del XIX.

Dentro del campo educativo, fue Enrico Pestalozzi (1746-1827), suizo germanoparlante nacido en Zurich, quien partiendo del pensamiento de Comenio desarrolló lo que se convirtió en fundamento de las doctrinas modernas sobre educación: el método intuitivo. Este método proponía desarrollar el conocimiento dejando que el niño descubra por sí mismo las características de los objetos a partir de la aplicación de los sentidos. El más importante de todos resultó ser el de la vista a través de la observación.

Como crítico del "verbalismo memorístico" de la educación de su época, fue un defensor de la acción:

Hacen esto, cuando antes de haber educado dócilmente su espíritu en la verdad y en la sabiduría por el conocimiento preciso de los objetos reales, se aventuran en el caos infinito de las palabras vanas y de las opiniones, y ponen, como fundamento de su carácter, y como primera educación de sus fuerzas, sonidos, discursos y palabras, en vez de las verdades de los objetos científicos. (PESTALOZZI 1999, p. 41).

La idea de que la educación debía estar basada en la experiencia lo llevó a plantear el concepto de "intuición” efectiva de las cosas. La intuición era para Pestalozzi el modo "natural" como el hombre aprende desde que nace.

Los nueve principios pestalozzianos marcaron la base del método intuitivo:

1- La actividad es una ley de la niñez; acostumbrar al niño a obrar, educar la mano.

2- Cultivar las facultades en su orden natural, desarrollar la mente y luego proveerla. 
3- Principiar por los sentidos y no decir jamás al niño lo que pueda descubrir por sí mismo.

4- Dividir cada asunto en sus elementos; una sola dificultad es bastante para un niño.

5- Proceder paso a paso y acabadamente. La medida de la instrucción no es la que el maestro puede dar, sino lo que el alumno puede recibir.

6- Que cada lección tenga un objeto mediato y otro inmediato.

7- Desarrollar la idea, dar la palabra que la representa y cultivar el lenguaje.

8- Pasar de lo conocido a lo desconocido, de lo simple a lo compuesto, de lo particular a lo general, de lo concreto a lo abstracto.

9- Primero la síntesis y después el análisis. No seguir el orden del asunto sino el de la naturaleza.

Aunque privilegiaba la utilización de los objetos, también aceptaba sus representaciones cuando no era posible observar los objetos reales.

En la Argentina, el método de enseñanza considerado tradicional, el verbalismo memorístico, comenzó a ser criticado a partir de la segunda mitad del siglo XIX, pero fue en el último cuarto de ese siglo cuando se vieron los primeros impactos de estas críticas. Esto se debió en parte a un cambio en la concepción pedagógica y metodológica de la enseñanza cuando las ideas de Comenio y Pestalozzi se articularon con diversos fragmentos del discurso positivista en la Argentina, especialmente el naturalismo biologista. Esta postura significaba la negación de cualquier realidad que trascendiera lo que podía alcanzarse mediante la ciencia experimental y explicaba el universo de los seres vivos mediante los procesos físico-químicos.

La máxima el estudio de las cosas debe hacerse en las cosas mismas comenzó a prevalecer acompañado de cuando esto no sea posible, recurrirá el maestro a aquellas representaciones que más se acerquen al estado y condiciones en que se ofrecen naturalmente los objetos.

Estos cambios en la metodología de la enseñanza coincidieron con la incorporación de las ciencias naturales, la historia y la geografía al currículum escolar. Es el período en el que distintos tipos de instituciones científicas y educativas fueron vistas como motores para acelerar el tránsito de la "barbarie" a la "civilización" y para ello se consideraban prioritarios otros conocimientos además de la lectura, la escritura y el cálculo. Se pensaba que estas 
incorporaciones lograrían cambios de hábitos y mentalidades en la población, una forma más racional de pensar la realidad para la creación de la Argentina "moderna".

Es este el momento en el que las láminas comenzaron a poblar las aulas.

\section{DE LA LÓGICA DE LA EXPERIMENTACIÓN Y EL DESCUBRIMIENTO}

Espacios de exhibición creados por nobles y mercaderes surgieron en la baja Edad Media (siglos XI al XV). En estos espacios, llamados "cámaras de maravillas"1 o "cámaras de tesoros", se atesoraba cualquier objeto que hubiera llamado la atención de su dueño (RICO MANSARD, 2004).

El siglo XVI es considerado como el período del "descubrimiento de las cosas", en el que los hogares de las familias ricas comenzaron a llenarse de objetos. Además del mobiliario y de objetos decorativos, se incorporaron otros que resultaban "novedosos", muchos de ellos pertenecientes a la antigüedad clásica: “[...] otra práctica mediante la que los valores renacentistas se hicieron parte de la vida diaria" (BURKE, 2000, p. 169). Se produjo un acercamiento al mundo "clásico" y una fuerte valoración de su acervo artístico; en parte, como medio de mantener o ascender en el status social.

Esta característica se articula con la pérdida paulatina del monopolio del conocimiento por parte de los monasterios o las universidades, y "[...] pasó a ser un elemento más del complejo entramado que fue la sociedad cortesana [...]" (PIMENTEL, 1999, p. 49).

Con el advenimiento de la modernidad, se asistió a una "objetivación de la cultura" y a una mayor "respetabilidad" de la innovación. Se inició un proceso de secularización del mundo y la realidad.

Durante el siglo XVII el gusto por los gabinetes de curiosidades se había difundido por Europa y se habían ampliado los especímenes provenientes de lugares apartados, el interés en lo curioso y lo exótico comenzó a declinar con la revolución científica de mediados del siglo XVII, el triunfo de Newton frente a la escolástica aristotélica.

La ciencia inductiva y observacional necesitaba de la experiencia y el descubrimiento. Los viajes militares y comerciales iban ahora acompañados por proyectos científicos y culturales. El viaje ahora concebido "[...] como observación disciplinada, como práctica científica de la inducción y arte de la descripción [...]" (CICERCHIA, 2005, p. 12) A partir

\footnotetext{
${ }^{1}$ En los países germánicos, fueron llamadas Kunst und Wunderkammern: habitaciones (cámaras) de arte y de maravillas.
} 
de los desarrollos suecos en el campo de las ciencias naturales, y de la construcción de Linneo de los fundamentos para una moderna taxonomía (Systema Naturae) los objetos debían ser descriptos, registrados, clasificados, catalogados y reproducidos e ilustrados.

Los viajeros colaboraron en popularizar la ciencia inductiva ubicando al mundo como un objeto observable. Para ello fueron acompañados por ilustradores que dejaban registro pictórico de lo que se observaba.

Durante el siglo XVIII en el contexto de la Ilustración y del desarrollo de la ciencia moderna, las imágenes adquirieron importancia fundamental como registro en el acto de conocimiento y como representación "neutra" de demostración. Esto fue impulsado por las asociaciones científicas como la Royal Society que reactivaron la tradición baconiana (empirista) con la intención de medir y representar al mundo dentro de una demarcación de lo racional.

\section{EL RECURSO DE LAS LÁMINAS}

La palabra encuentra en la ilustración el complemento indispensable o su mismo sustituto. Permite acercar al estudiante detalles externos e internos de los objetos de estudio.

Las láminas escolares forman parte del material escolar ilustrativo junto a otros elementos como gráficos, fotografías, cuerpos plásticos, proyecciones audiovisuales, etc. También pueden ser nombradas como murales o ilustraciones.

Con sus imágenes y colores permitían representar lo externo y lo interno, lo visible y lo no visible de las plantas, animales, cuerpo humano, etc. materializando de alguna manera las clasificaciones que las ciencias habían construido sobre la naturaleza. También contribuían a imaginarse escenas de la historia en tiempos pretéritos, costumbres, culturas, etc. acompañando la construcción de la historia del país y las distintas representaciones de ciudadanía.

Las primeras láminas para uso escolar surgieron en Prusia alrededor de 1820. En sus orígenes fueron confeccionadas en formatos pequeños: 20 x $30 \mathrm{~cm}$ y presentaban escenas y objetos para la enseñanza elemental: mascotas, utensilios de cocina, actividades como la caza o los ciclos de las estaciones para que aprendan sobre la vida de los animales, los nombres y características de los objetos y algunas profesiones (BUCCHI, 1998) 
Con el tiempo el tamaño de las láminas se amplió y comenzaron a cubrir una gran cantidad de temas relacionados con las disciplinas escolares. En la segunda mitad del siglo XIX se hacen comunes en otros países europeos y americanos. Se considera que la "era dorada" de las láminas fue entre 1870-1920.

Los editores/impresores provenían del mundo de la edición de libros, los ilustradores del campo de libros de cuentos, pintores y algunos cercanos al mundo de las ciencias naturales.

"La ilustración es la presentación de asuntos, hechos, ejemplos, etc., que contribuyan a aclarar los pensamientos tendientes a explicar una lección" (IMPERATORE, 1954, p. 52).

En la Argentina a fines del siglo XIX y principios del XX las escuelas, sobre todo las normales, comenzaron a formar sus gabinetes de Física, de Química y de Historia Natural y las escuelas primarias a formar sus "museos escolares" con objetos, modelos y láminas importadas de Alemania, Francia, Inglaterra, Escocia, Estados Unidos de Norteamérica, Italia, etc.

Dentro de las aulas los maestros empezaron a utilizar las láminas para acompañar sus clases. Mediante la guía del maestro, por ejemplo en una clase de "zoología" sobre el gusano de seda, los alumnos y las alumnas debían en primer término observar las imágenes y describirlas. Ubicar al gusano dentro de una clasificación: Familia (Artrópodo), Clase (Insecto) y Orden (Lepidóptero). Describir sus partes (cabeza, tórax y abdomen) y su ciclo biológico (las larvas, las ninfas y los adultos). Finalmente con la ayuda de imágenes u objetos si los hubiere, se llegaba al proceso de industrialización y comercialización de la seda. Prevalecían las lecciones expositivas e interrogativas del tipo socrático (diálogo dirigido).

Pero en algunas clases había un inconveniente, las láminas no representaban "lo nacional" sino las "realidades" de otros lugares ${ }^{2}$.

Hacia finales de siglo XIX, en Argentina había dificultades de "orden técnico": falta de producción de papel nacional, escasez de imprentas con tipos adecuados y costos elevados. Para este momento, el editor como "empresario específico" no estaba presente en el escenario

\footnotetext{
${ }^{2}$ En el Museo de las Escuelas hay láminas importadas cuya procedencia son Editorial: Antonio Vallardi Editore, Italia, Editorial: G.V. Paravia y C., Torino, Italia Editorial: W. y A. K. Johnston Ltd, Edimburgo, Editorial: Imprenta de J. F. Schreiber, Essalingen, Alemania.
} 
nacional. La importación seguía siendo más económica que la producción nacional de buena calidad.

Esto sucedía en el marco de una gran inmigración europea y la presión por parte de las distintas comunidades extranjeras por mantener sus tradiciones culturales. Con la intención de nacionalizar la enseñanza se recurrió a la Historia, la Geografía y la Lengua, pero también las Ciencias Naturales debían pensarse para tal fin.

Las posibilidades económicas y técnicas de la industria nacional limitaban la producción de láminas en el país. Pero con el tiempo, sobre todo a partir de la década de 1930, la producción nacional multiplicará en número las láminas escolares y éstas terminarán reemplazando a los objetos en las aulas por razones de practicidad y economía.

Paradójicamente, a partir de la década de 1930 comienzan a entrar en las escuelas los métodos activos que sostenían un mayor protagonismo por parte de los niños en el proceso de aprendizaje. Aunque se sigue sosteniendo que no hay diferencia entre el método que emplea el científico y el niño, comienzan cambios en la didáctica que propugnaban simplificar los métodos científicos y proponían que el aspecto cuantitativo debía ceder paso al cualitativo. Para ello se aconsejaba que los niños tomaran contacto directo con el mundo natural empleando la observación directa, la experimentación personal y la reflexión mediante la injerencia del niño en el proceso de la adquisición y la expresión de sus ideas. Los alumnos podían observar el vapor de agua de la pava, diseccionar el interior de animales pequeños como la rana, fraccionar minerales, construir aparatos de demostración, manejar el microscopio, construir jaulas, acuarios, insectarios, etc. El dibujo debía acompañar la observación y cuando conviene modelarlo. Desde estas posturas las láminas debían pasar a ser auxiliares de los objetos y no reemplazar al objeto real. Y las que se utilizaran debían mostrar a los animales y las plantas en su medio real, ya no como seres aislados.

Clotilde Guillén de Rezzano en su "Didáctica especial” (1938) ya aconseja la utilización de films educativos que muestran células, tejidos, funciones, etc.

La clase del caracol: Consigue un caracol vivo. ¿Dónde oculta su cuerpo cuando se molesta? Colócalo sobre un vidrio y observa a través cómo consigue caminar. Invierte el vidrio, ¿Por qué se sostiene? ¿Dónde viven? ¿De qué se alimentan? Conseguir una cucaracha, una mariposa y comparar los animales. 
La continuación del uso masivo de las láminas quizá pueda explicarse por cuestiones económicas y de practicidad y por otro lado, el protagonismo del método intuitivo continuó hasta la década de 1980. La incorporación de principios del aprendizaje activo no implicó, necesariamente, un corte con la concepción intuitivista: "De hecho, diversos autores como Aebli (1958), Bowen (1992b), Not (1983), Obregón, Saldarriaga y Ospina (1997) señalan que influyentes pedagogos de la Escuela Nueva, tal es el caso de Decroly y Montessori, mantuvieron fuertes lazos conceptuales con el asociacionismo sensualista" (FELDMAN, 2004, p. 10). Los que se modificaron fueron algunos campos epistemológicos como el de la biología, generalizando el estudio de los seres vivos antes que el estudio de los preservados observándolos en un esquema general de vida. La disección de animales se rechazó por una cuestión ética. En este contexto y con la incorporación paulatina de nuevas tecnologías como el video e Internet, los seres desecados o representados en láminas dejaron de tener sentido. Los objetos de la naturaleza y sus representaciones estáticas fueron reemplazados por los procesos y los sistemas complejos en el conocimiento.

También es verdad que las láminas no desaparecieron totalmente de los muros de las aulas, pero refieren fundamentalmente a eventos, conmemoraciones, resultado de los trabajos de los alumnos o para ilustrar el trabajo realizado sobre un tema. Como afirma Feldman (2004) ya no son elementos para la apreciación sensible como base y primer paso del conocimiento.

\section{UNA MIRADA SOBRE LA IMAGEN}

El lugar del texto en las láminas tiene una lógica diferente a otras relaciones de texto-imagen como en los libros de texto, en los carteles, en los periódicos. En algunos casos son solo textos que titulan, nombran, presentan, el tema que va a contener la lámina. En otros casos, clasifican, ordenan el universo...descompone la imagen en palabras para construir un relato escolarizado de las ciencias.

Las escuelas están poblabas de imágenes, carteles, dibujos en los pizarrones, graffitis, fotografías, láminas, etc. Estas imágenes son múltiples como múltiples son sus usos y objetivos perseguidos. Las láminas representan una imagen específica ya que su principal función ha sido la de "transmitir" saberes. 
La escuela utilizó láminas- en algunos casos las sigue usando - como medios didácticos para la enseñanza, fundamentalmente llevando el mundo exterior, muchas veces inalcanzable, a los muros del aula pretendiendo normalizar los saberes y los modos de interpretación de la realidad. Esto no significa que sea posible anclar la imagen a un solo significado ya que son los observadores los que terminan construyendo los sentidos. Cuando hablamos de imágenes“...debemos tener en cuenta sus poderes, que son polisémicas, ya que no todos vemos lo mismo cuando miramos" (ABRAMOWSKY, 2007, p. 35).

Hay dimensiones que no suelen tomarse en cuenta en la práctica escolar, las imágenes no solo muestran un contenido sino que además despiertan sensaciones relacionadas con lo estético o lo emocional: "Según la historiadora del arte Laura Malosetti Costa, lo que le otorga primacía a las imágenes visuales en materia de aprendizaje es su poder de activación de la atención, de las emociones- en el observador" (ABRAMOWSKY, 2007, p. 34).

Pero hay otra dimensión además de la personal que también tenemos que tener en cuenta, la histórica. Lo que representan las láminas hay que analizarlo en sus contextos históricos y geográficos, ya que el universo simbólico compartido es diferente según los diversos espacios y momentos socio-culturales. De un área cultural a otra, de experiencias culturales y socio-económicas disímiles, de una generación a otra, los actores descifran sensorialmente el mundo de un modo diferenciado.

Desde el sentido común de los que las observan, las láminas aparecen despojadas de identidad y cargadas de "neutralidad" con una valoración de "verdad" casi igual al que se le otorga a la palabra impresa. Esto se cumple con más eficiencia cuando se habla de materiales gráficos científicos. En ellos parecería que las imágenes tienen una mayor cercanía con la realidad o si se quiere, que la sustituyen cabalmente. Un recorte legitimado del conocimiento científico que se traspone al universo escolar. Para ello las láminas designan y explican, encierran a la Naturaleza, la historia, la vida de los hombres y las mujeres en un cuadro, acercando-colocando el afuera dentro de las paredes del aula con representaciones lo más fieles posibles a la realidad. Las que están relacionadas con las Ciencias Naturales tienen la característica que desarman, fragmentan en piezas el universo visible (SZIR, 2006).

Por otro lado, las imágenes presuponen una técnica para concretarse y exteriorizarse (el dibujo, la impresión) manteniendo una ambigüedad entre lo real y lo simbólico. La ilustración como producto de esas técnicas nos dirige la mirada, pero hace falta la 
imaginación para darle vida a lo que se observa ya que las imágenes son representaciones estáticas.

El dibujo de Magritte de una pipa (versión de 1926) como dice Foucault (2012) es simple como una página extraída de un manual de botánica: una figura y un texto que lo nombra. Sin embargo el texto que acompaña la imagen parecería que genera una extrañeza "Esto no es una pipa”. Foucault se pregunta ¿Hace falta decir: mi Dios, qué tonto y simple es todo esto; este enunciado es perfectamente verdadero, ya que es muy evidente que el dibujo que representa una pipa no es él mismo una pipa? Lo que desconcierta es que es inevitable relacionar el texto con el dibujo.

Las láminas escolares fueron confeccionadas para no generar dudas sobre lo que se observa, ni siquiera para que el que las mira piense que esa no es la realidad misma. Fueron pensadas para reemplazar lo que, por la lejanía, la comodidad del docente o la propia observación no puede ser llevada al aula.

\section{LAS POSIBILIDADES EXPOSITIVAS DE LAS LÁMINAS EN LOS MUSEOS}

En este punto propondré brevemente algunas categorías que podrían utilizarse para una exposición museística.

En principio debemos decir que el componente artístico de las láminas es un valor fundamental que habla por sí solo. La mayoría de ellas son extrañas a nuestras representaciones visuales en la actualidad y muchas nos invitan al goce estético.

Amapola y celedonia: Antonio Vallardi Editore, Milán, Italia. Importado por Editorial Vallardi Americana. s/f.

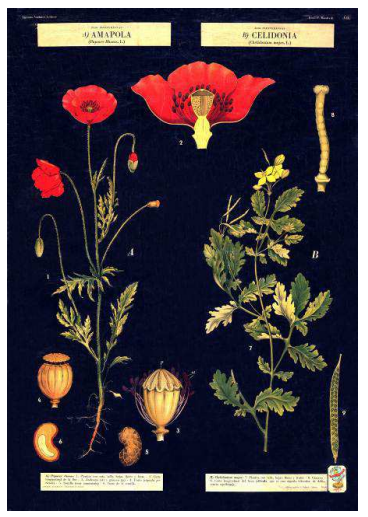

Fuente: Museo de las Escuelas. 
Lenguaje en acción: para observar, pensar y hablar: La Obra S.R.L. Argentina. s/f

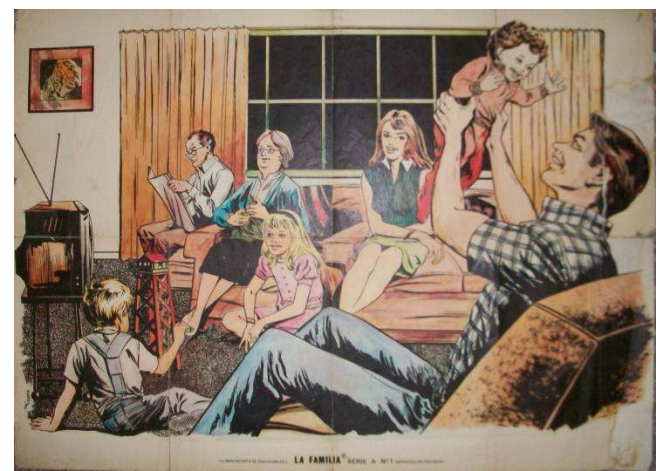

Fuente: Museo de las Escuelas.

Por otro lado, para el caso de los países latinoamericanos especialmente, nos permiten acercarnos a varias problemáticas:

La importación/no producción de materiales nacionales.

Las grandes inmigraciones del siglo XIX y XX.

La colonización del conocimiento.

Las rupturas epistemológicas en las ciencias.

La introducción del método intuitivo.

Las disputas internas sobre el origen y el uso de las imágenes.

Las continuidades y rupturas en las prácticas y representaciones sociales.

\section{REFLEXIONES FINALES}

El análisis de las láminas escolares aporta a la Historia de la Educación y a los Museos de la educación la mirada desde la historia cultural.

Desde este punto de vista, vemos a la escuela como una entidad productora de una cultura específica, original, que puede ser considerada como objeto histórico. En un principio, el concepto de cultura escolar se fue definiendo como "[...] el conjunto de normas que definen los saberes a enseñar y las conductas a inculcar, y un conjunto de prácticas que permiten la transmisión de estos saberes y la incorporación de estos comportamientos [...]" (JULIA, 1995, p.354). La historia de las prácticas culturales es la más difícil de reconstruir porque no deja huellas: estas conforman la "caja negra" (DEPAEPE, SIMON, 1995) de la historia de la educación, al no permitir visualizar el cotidiano escolar. Por este motivo, comenzó también un proceso de valorización de las fuentes materiales de la historia de la 
escuela, "[...] excluidas hasta no hace muchos años del patrimonio educativo por su subestimación frente a los testimonios de la cultura letrada [...]" (ESCOLANO BENITO, 2007, p. 15). Los objetos pasaron a ser concebidos como un texto que puede ser "leído", comprendido, interpretado en sus contextos de producción, circulación y apropiación; como "artefactos culturales" que encuentran significado y sentido en un proceso histórico.

Aunque el concepto es muy difícil de definir, por lo abarcativo que resulta, este marco referencial posibilitó el análisis de objetos de estudio variados y olvidados por la historia de la educación y, además, permitió el desarrollo de "centros de memoria" y museos de lo escolar. Los objetos y las representaciones, junto con los documentos escritos u orales de la historia de la educación, se constituyeron en objetivos en la estrategia de recuperación patrimonial de la sociedad.

Dentro de la cultura escolar, la "cultura material" puede aportar significaciones culturales a una historia de la escuela. "La escuela nos ha legado todo un utillaje material, un ajuar ergológico (como dirían los antropólogos) que es reflejo de su cultura empírica, de la tradición corporativa adscrita al oficio de enseñante, y en parte también de los discursos teóricos y normativos que se han proyectado sobre la educación formal" (Escolano Benito, 2007: 17). Sin adherir al concepto de "reflejo", ya que los objetos, a pesar de permanecer en el tiempo, van cambiando sus significados y usos, queremos resaltar la idea de que las escuelas son lugares donde se construyen culturas materiales y tecnológicas específicas (LAWN; GROSVENOR, 2005), pero también las escuelas son receptoras (no pasivas, por cierto) de culturas producidas por fuera de ellas. Y es en las relaciones sociales donde hay que buscar la significación de los hechos materiales (SARMIENTO RAMÍREZ, 2007). Históricamente, quienes han asignado mayor interés en la cultura material son los arqueólogos, antropólogos, historiadores de la tecnología, geógrafos culturales, museólogos. Pero el principal problema que se presentaba es que, por lo general, se interpretaban fuera de sus contextos y fuera de los discursos que los producían, separándolos como elementos no humanos y sin tener en cuenta que los usuarios, de alguna manera, son conformados a su vez por los objetos, ya que estos son diseñados para producir ciertas acciones. Consideramos que las personas, los objetos y las prácticas están estrechamente relacionados. 


\section{BIBLIOGRAFÍA}

ABRAMOWSKI, Ana "El lenguaje de las imágenes y la escuela ¿Es posible enseñar y aprender a mirar?" en revista El Monitor, no 13. Ministerio de Educación, Ciencia y tecnología de la Nación, 2007.

BUCCHI, Massimiano. Images of Science in the classroom. Wall Charts and science education, 1850-1920. The British Journal for the History of Science, 1998.

BURKE, Peter. El Renacimiento Europeo. Barcelona, Crítica, 2000.

CICERCHIA, Ricardo. Viajeros. Ilustrados y románticos en la imaginación nacional. Buenos Aires, Troquel, 2005.

COMENIO, Juan Amós. Didáctica Magna. Madrid, Akal, 1986.

CRUDER, Gabriela. La educación de la Mirada. Sobre los sentidos de la imagen en los libros de texto. Buenos Aires, La Crujía, 2008.

DEPAEPE, M. y SIMON, F. "Is there any place fort the history of education in the History of Education?", en Paedagogica Historica, XXX-1, n. 10, 1995.

ESCOLANO BENITO, Agustín. La cultura material de la escuela, en el centenario de la Junta para la Ampliación de los Estudios 1907-2007. Berlanga de Duero, España, CEINCE, 2007.

FELDMAN, Daniel. "Imágenes en la historia de la enseñanza: la lámina escolar", en Educação \& Sociedade, v. 25, n. 86, Campinas, 2004.

GUILLÉN DE REZZANO, Clotilde. Didáctica especial para tercer año de las Escuelas Normales. Buenos Aires, Kapelusz, 1938.

IMPERATORE, Amanda. Lecciones de Didáctica. Buenos Aires, Librería del Colegio, 1954.

JULIA, Dominique. "La cultura escolar como objeto histórico", en Menegus, M. y González, E. (coord.): Historia de las Universidades modernas en Hispanoamérica. Métodos y fuentes. UNAM, México, 1995.

LAWN M. Y GROSVENOR, I. Materialities of Schooling design, technology, objects, routines. Inglaterra, Symposium books, 2005.

PESTALOZZI, J. E. "Las veladas de un ermitaño", en Sobre educación: Kant, Pestalozzi y Goethe. Composición y traducción de Lorenzo Luzuriaga. Biblioteca Virtual Miguel de Cervantes, 1999.

PIMENTEL, Juan. "La monarquía hispánica y la ciencia donde no se ponía el sol”, en Lafuente, Antonio y Moscoso, Javier; Madrid: Ciencia y Corte. Madrid, 1999. 
RICO MANSARD, Luisa F. Exhibir para educar. Objetos, colecciones y museos de la ciudad de México (1790-1910). México, Pomares, 2004.

ROUX, Hebe M. La construcción de la imagen en la escuela. Enseñar a través de arquitecturas, rituales y repertorios visuales. Buenos Aires. Escuela de Capacitación Docente - CEPA. Disponible en: v. 31, n. 2, Science and the Visual, 2013.

SARMIENTO RAMÍREZ, Ismael. "Cultura y cultura material: aproximaciones a los conceptos e inventario epistemológico", en Anales del Museo de América, n. 15, p. 217-236, 2007.

SZIR, Sandra M. Infancia y Cultura Visual. Los periódicos ilustrados para niños (18801910). Buenos Aires, Miño y Dávila, 2006. 